FedUni ResearchOnline

https://researchonline.federation.edu.au

This is an Accepted Manuscript of an article published by Taylor \& Francis in Communications in Soil Science and Plant Analysis on 29/01/2018, available online:

https://doi.org/10.1080/00103624.2017.1395442 


\section{Assessment of error sources in measurements of field pH: effect of operator 2 experience, test kit differences and time-of-day}

3 Nathan J. Robinson ${ }^{125}$, Sorn Norng ${ }^{3}$, David B. Rees ${ }^{3}$ Kurt K. Benke ${ }^{34}$ and Michelle Davey ${ }^{3}$

$5 \quad{ }^{1}$ Agriculture Research Branch, Department of Economic Development, Jobs, Transport and Resources

6 (DEDJTR) - Bendigo Centre, Cnr Midland Hwy and Taylor Street, Epsom 3554, Victoria Australia.

$7 \quad{ }^{2}$ Faculty of Science and Technology, Federation University Australia, University Drive, Mt Helen 3353,

8 Victoria Australia.

$9 \quad{ }^{3}$ Agriculture Research Branch, Department of Economic Development, Jobs, Transport and Resources (DEDJTR) - Parkville Centre, 32 Lincoln Square North, Parkville 3052, Victoria Australia.

${ }^{4}$ School of Engineering, University of Melbourne, Melbourne 3010, Victoria Australia.

${ }^{5}$ Corresponding author: Email: Nathan.Robinson@ecodev.vic.gov.au; Phone: (613) 54304320

\section{Abstract}

Various methods exist to measure soil $\mathrm{pH}$, and while there is general agreement between existing published laboratory and field based methods, the latter are subject to uncertainties including test kit reliability, accuracy, precision and environmental factors. The contribution of this study is to quantify three uncertainties that affect the conversion between field $\mathrm{pH}$ and laboratory $\mathrm{pH}$ measurements, namely operator experience, choice of test kit and the time-of-day for measurement. Soil samples from western Victoria, representing the $\mathrm{pH}$ range 4.5 to 10.0 , were used in a randomised complete block design with ten assessors split into two groups representing experienced and inexperienced users. Statistical analysis of laboratory and field $\mathrm{pH}$ was based on using the Maximum Likelihood Functional Relationship (MLFR) to determine if there was any bias between the two methods. kits. 
Keywords: bias, relationship, Maximum Likelihood Functional Relationship (MLFR), impurities, harmonization.

\section{Introduction}

Soil $\mathrm{pH}$ is the most frequently measured soil chemical property and provides invaluable background context to understanding chemical, physical and biological interactions and behaviours of soil and regolith with the biosphere and hydrosphere. Not only does $\mathrm{pH}$ have a critical role, as the expression of acidity or alkalinity and its impact on the availability and solubility of nutrients, it is also used for soil classification purposes, land use and land capability assessment and for modelling and understanding of agro-ecosystems.

Internationally there are numerous methods used to measure soil $\mathrm{pH}$ in field and laboratory environments. In the laboratory, different ratios of soil and water or saline solutions are used. Historically, in Australia, laboratories have measured $\mathrm{pH}$ in suspensions of soil and water by shaking one part soil with 5 parts water for one hour (ISO 10390:2005; Method 4A1 in Rayment and Lyons, 2011). To better account for seasonal variability in insoluble salts due to rainfall or management interventions, such as fertilizer addition (White 1969), water was supplemented with a weak salt solution, i.e. $0.01 \mathrm{M} \mathrm{CaCl}_{2}$ (Method 4B1 in Rayment and Lyons, 2011). Arguably, laboratory pH methods are the most reliable in comparison to field $\mathrm{pH}$ procedures; however, field based $\mathrm{pH}$ assessment is rapid, inexpensive and results are instantly available to users, such as soil scientists, extension and advisory providers.

Field measurement of soil $\mathrm{pH}$ (hereon referred to as field $\mathrm{pH}$ ) has been in use for 100 years, with methods required to be rapid, accurate, cheap and easily ascertained (Wherry 1920; Mason and Obenshain 1939). The sequential development of $\mathrm{pH}$ measurement includes methods that added salt solution to the soil (e.g. $\mathrm{CaCl}_{2}$ or $\mathrm{KCl}$ ) and those that added water to the soil and observed colour changes of indicators as related to concentrations (Wherry 1920). As field methods evolved, further comparison studies were undertaken to assess the usefulness of indicator methods in comparison with standard electrometric laboratory methods (Mason and Obenshain 1939). In Australia, enhancements 
to the makeup of indicator solution and methodology to apply barium sulphate onto a soil-indicator paste (Raupach 1950; Raupach and Tucker 1959) led to the establishment of the colorimetric procedure (Method 4G1 in Rayment and Lyons, 2011) that is still widely used today.

Field $\mathrm{pH}$ provides a simple, expedient and reliable approach to measuring $\mathrm{pH}$ for soil survey and advisory services at various scales (Raupach and Tucker 1959; National Committee on Soil and Terrain 2009). Measurement of field pH using the colorimetric method of Raupach and Tucker (1959) has been undertaken as standard practice in soil and land surveys across Australia for over 60 years. Extensive collections of field $\mathrm{pH}$ measurements exist in state, territory and national databases, such as the Victorian Soil Information System (VSIS, Hunter et al. 2010) and Australian Soil Resource Information System (ASRIS, www.asris.csiro.au). Also contained within these databases are less frequent companion sets of laboratory $\mathrm{pH}$ observations for $\mathrm{pH}$ in 1:5 soil-to-water suspension (hereon referred to as $\mathrm{pH}_{\mathrm{w}}$ or $\left.\mathrm{lab} \mathrm{pH}\right)$, and with $0.01 \mathrm{M} \mathrm{CaCl}_{2}$ extract.

Complementary field and laboratory measurements of soil $\mathrm{pH}$ on samples enable comparison of these methods and evaluation of method performance. Comparative studies of various $\mathrm{pH}$ measurement modalities have been carried out in the past (Mason and Obenshain 1939; Steinhardt and Mengel 1981; Slattery and Ronnfeldt 1992). It has been demonstrated that there is reasonable agreement between lab $\mathrm{pH}$ and field $\mathrm{pH}$, measured from the same soil sample where a single operator was responsible for field measurements (Baker et al. 1983). Steinhardt and Mengel (1981) specifically evaluated the performance of a colorimetric indicator field method against the laboratory method for determining the accuracy of predicting soil $\mathrm{pH}$. However, while the authors identified some of the potential error sources that result in variation between field and laboratory $\mathrm{pH}$ methods, the scope of this and early studies failed to investigate factors affecting the strength of agreement between different methods of measuring $\mathrm{pH}$ for extremely acid to alkaline soils.

Globally, there is a current focus on the delivery of digital soil maps (McBratney et al. 2003) exploiting available legacy soil data (Carré et al. 2007) for initiatives such as the GlobalSoilMap project (www.globalsoilmap.net). For many states, territories and nations, significant deficiencies may exist in measured, accessible and available laboratory $\mathrm{pH}$ data. As a consequence, there is a potential role for legacy $\mathrm{pH}$ observations over geographically widespread areas to complement available laboratory $\mathrm{pH}$ 
data for digital soil mapping purposes (de Caritat et al. 2011; Hopley et al. 2014). The extensive collections of field $\mathrm{pH}$ observations in state, territory and national government organisation databases may also be valuable in establishing a baseline of soil condition where design-based monitoring systems are absent.

At present, the documented $\mathrm{pH}$ datasets for field $\mathrm{pH}$ and lab $\mathrm{pH}$ measurements are large, but limited by the numerous confounding error sources that contribute to measurement uncertainty. Some of these unaccounted sources of uncertainty in field $\mathrm{pH}$ measurement include:

- assessor (experience level);

- $\quad \mathrm{pH}$ test kits (different brands);

- $\quad$ soil characteristics ( $\mathrm{pH}$ range and value);

- time-of-day (light quality), and

- $\quad$ age of test kit.

From practical field experience in conducting field $\mathrm{pH}$ measurements, there are many effects that could potentially bias the relationship between lab $\mathrm{pH}$ and field $\mathrm{pH}$. For example, it has been reported that although Australian measurements of the spectral content of daylight have been similar to northern hemisphere measurements, there is a higher level of irradiance in the ultraviolet spectral region (Dixon 1978). The effect on colour card matching and $\mathrm{pH}$ assessment over the course of the day is unknown but there may be bias towards a higher $\mathrm{pH}$ reading.

Print quality of colour cards provided by different commercial field $\mathrm{pH}$ kits may introduce inaccuracy and uncertainty in $\mathrm{pH}$ test kits. The performance of indicator test kits can deteriorate over time due to solvents with aged dyes or impurities (Mason and Obenshain 1939). Also, batch-to-batch variations in the kit indicators and solvents may introduce perceptible shifts in performance. Very little research has been reported on these effects or on the potential impact of colour interpretation in the field.

The aim of this study is to address this gap in knowledge on sources of uncertainty affecting soil $\mathrm{pH}$ determination by investigating how those factors may affect the relationship between field and lab $\mathrm{pH}$ and quantifying the potential bias introduced by each factor. Two experiments to account for error 

Relationship (MLFR) as proposed by Ripley and Thomson (1987) were designed to test the following

111 hypotheses:

112 1. there is a significant assessor effect on the analytical bias between field and lab $\mathrm{pH}$;

113 2. there is a significant $\mathrm{pH}$ level effect, and

114 3. there is a significant test kit effect.

The effect of light quality was considered as time-of-day and has been used as a blocking factor in this study. The findings from these experiments will provide support for recommendation of a more "robust" measurement methodology of field $\mathrm{pH}$ in future applications such as soil surveys and contribute to the harmonization of existing legacy field $\mathrm{pH}$ datasets with laboratory $\mathrm{pH}$ data used in digital soil mapping and monitoring applications.

\section{Materials and methods}

Materials

\section{Soil samples and laboratory analyses}

126 Samples were selected from over 1800 soil monitoring and reference site samples that were analysed

127 for $\mathrm{pH}_{\mathrm{w}}$ between 2011 and 2014. These samples were selected as they correspond with various $\mathrm{pH}$ levels represented in commercially available field $\mathrm{pH}$ test kits $(4.5,5.0,5.5$ (x2), 6.0, 6.5, 7.0, 7.5, 8.0, 8.5, 9.0, 9.5 and 10.0). The prepared $<2 \mathrm{~mm}$ samples (Figure 1) from sites across western Victoria obtained initial laboratory $\mathrm{pH}$ values \pm 0.02 of the field kit $\mathrm{pH}$ levels. Samples were included from various Soil Orders of the Australian Soil Classification (Isbell 2002) including Chromosols,

132 Dermosols, Sodosols, Calcarosols and Vertosols. Key soil properties, including depth of sample, are presented in Table 1. 
Laboratory analysis for the experiments was undertaken in triplicate to estimate error in laboratory measurement. Measurements were determined using a Radiometer Analytical (Lyon, France) titration system comprising PHM92 pH meter, CDM240 conductivity meter and SAC950 sample changer. The instrument was calibrated according to the manufacturer's specifications with a reported laboratory precision of $< \pm 0.1 \mathrm{pH}$ units. Initial $\mathrm{pH}_{\mathrm{w}}$ results were from numerous batches, and as a consequence there is greater batch-to-batch variability in these results in comparison with the second and third measurement that were obtained in the single batch. All batches included two control samples, as recommended, to account for instrument drift (Laslett and MacBratney 1990).

\section{Psychophysical assessment of field $\mathrm{pH}$}

Experimental assessment of field $\mathrm{pH}$ using the $\mathrm{pH}$ test kit followed the standard protocol for a psychophysical experiment involving human perceptual judgements recorded on a psychometric scale (Benke et al. 1988). Psychophysical measures were in the form of colour assessments using a colour card with 16-step scale for matching colour against treated soil samples for field $\mathrm{pH}$ determination. To compare and contrast regular users of the field $\mathrm{pH}$ kit such as trained pedologists involved in soil and land survey (Experienced group) against those that may have used a kit irregularly or not at all (Inexperienced group), two groups of assessors (Assessor Type) were selected based on their test results from an online colour-blind test called the Farnsworth-Munsell 100 Hue Colour Vision Test (Farnsworth 1943). The ten subjects were male and female technical and scientific staff volunteers. All subjects had 20/20 vision wearing their normal correction. Ages of subjects ranged from 35 to 60 years. Each subject carried out three colour assessment sessions (two on the first day at Early and Late afternoon and one on the second day at noon).

\section{Field $p H$ test kits}


Two commercially available soil pH test kits were used in this study (referred to as Kit 1 and Kit 2) and were based on the Raupach and Tucker (1959) field $\mathrm{pH}$ determination procedure. Both kits used the same assessment procedure where a soil sample ( $<1$ teaspoon) was mixed with the indicator solution until a thick paste was established. The paste is then dusted with $\mathrm{BaSO}_{4}$ (barium sulphate) powder (used as an optical enhancing agent) and the colour assessed against the colour card after 1 to 2 minutes to find a nearest match.

\section{Time-of-day (light quality)}

One of the major influencing factors in colour differentiation is light quality (or lack of it) which reflects the background environmental lighting, glare from the light source and veiling reflection. This is directly influenced by the time-of-day for measurement of field $\mathrm{pH}$. Time-of-day, in the remainder of this paper, will be used interchangeably with light quality. Since time could not be randomised, it was fixed as a blocking factor with two classes: 1PM and 5PM.

It was decided that early and late afternoon (Period) would be good surrogates for good and poor quality light respectively. Both experiments were conducted outside in April 2015 on sunny days with clear blue skies.

\section{Experimental design}

Two experiments were conducted to test hypotheses 1 and 2 (Experiment 1) and hypothesis 3 (Experiment 2).

\section{Experiment 1}

At each time period, samples were randomly allocated to the 10 assessors for field $\mathrm{pH}$ assessment. Each participant was randomly allocated samples of the $13 \mathrm{pH}$ levelsto detect if any significant difference in 
colour differentiation between assessors exists and if differentiation is consistent across the full spectrum of colours (or $\mathrm{pH}$ levels).This was phase A of Experiment 1.

Phase B of this experiment involved each assessor completing $\mathrm{pH}$ assessments in triplicate on at least $3 \mathrm{pH}$ levels (for example, Assessor 1 might be allocated $\mathrm{pH}$ levels 4.0, 6.5 and 9.5 and Assessor 2 might receive $\mathrm{pH}$ levels, 4.5, 6.0 and 10, etc). One assessor in each group (Experienced or Inexperienced) assessed $\mathrm{pH}$ levels on four samples to complete the set of measurement errors for each of the $\mathrm{pH}$ levels*Assessor Type. This data was combined with the triplicate lab $\mathrm{pH}$ data to provide measurement error estimates on both field $\mathrm{pH}$ and lab $\mathrm{pH}$ enabling an assessment of potential bias by fitting models that accommodate for errors in both field and lab $\mathrm{pH}$.

The above two phases (A and B) were combined into one single experiment in a full factorial of Assessor*pH level in a randomised complete block design (RCBD), where time-of-day were used to group $\mathrm{pH}$ assessments as the blocking factor. Phase $\mathrm{B}$ was incorporated using the same design but with an extra randomisation of Assessor to $\mathrm{pH}$ level for conducting triplicate field $\mathrm{pH}$ measurements. The same randomisation was fixed for 1PM and 5PM for practical reasons, that is, Assessor and $\mathrm{pH}$ level pairing were consistent and an extra replication for a better estimate of the Assessor consistency.

\section{Experiment 2}

In this experiment, Kit Type, Assessor (and Assessor Type) and $\mathrm{pH}$ level were included in a split-plot design where Assessor was used as a blocking factor, $\mathrm{pH}$ level was the whole-plot factor and Kit Type was the sub-plot factor respectively.

\section{Statistical analyses}

\section{Exploratory analyses}


Trellis plots were used to plot data from both experiments in order to explore any potential relationship between variables as a basis to inform further formal statistical modelling. In Experiment 1 (phase A), field $\mathrm{pH}$ was plotted against lab $\mathrm{pH}$ in panels (Figure 2), where each trellis/panel represented each Assessor (A-J). In the same experiment, field $\mathrm{pH}$ was again plotted against lab $\mathrm{pH}$ in panels, but this time each trellis/panel represented Assessor Type (Experienced and Inexperienced).

In Experiment 2, field $\mathrm{pH}$ was again plotted against lab $\mathrm{pH}$ in panels, but this time the panels were extended to include a double layer of Assessor and Kit Type where each panel represented a combination of those two factors.

All plots were constructed using the lattice 0.20-31 package (Sarkar 2008) in R and implementing modified codes to accommodate our data structure and visual display requirements. All plots were performed in the R statistical software (R Development Core Team 2015).

Formal analyses

To compare the performance of Assessors in Experiment 1 (phase A) and Kit Type in Experiment 2, a relevant measure was necessary to compare how well an assessor managed to measure the field $\mathrm{pH}$ of their allocated samples. The closer the field $\mathrm{pH}$ values are to the lab $\mathrm{pH}$ values, the higher the precision of the Assessor or Kit Type in determining $\mathrm{pH}$ value. An absolute difference between field $\mathrm{pH}$ and lab $\mathrm{pH}$ was used as the variable of interest.

In Experiment 1 (phase A), the absolute difference was analysed using Analysis of Variance (ANOVA). The treatment structure was specified with fully factorial effects for Assessor Types in full factorial combination with Level ( $\mathrm{pH}$ levels). The treatment structure was set as Assessor Type* $\mathrm{pH}$ level, the blocking structure was specified as Samples nested within Assessor and nested within Period (Period/Assessor/Sample).

To detect potential bias between lab $\mathrm{pH}$ and field $\mathrm{pH}$, an estimated measurement error for both methods (field method and lab method) was produced in Experiment 1, phase B. Given that triplicate samples 
were allocated to both the Experienced and Inexperienced groups on both experimental periods (Early and Late afternoon), it is possible to look at the potential bias for all combinations and of Assessor Type*Period as well as a combined data (ignoring the groups).

Given that data were available for all combinations of time-of-day and Assessor Type, four scenarios were tested: 1. Experienced and 1PM; 2. Experienced and 5PM; 3. Inexperienced and 1PM; and 4. Inexperienced and 5PM. For each combination and the combined data, two models for field $\mathrm{pH}$ and lab pH were fitted: Linear Model (LM) and the Maximum Likelihood Functional Relationship (MLFR). Both models were adapted to test (1) if the intercepts were significantly different from 0, and (2) if the slopes were significantly different from 1 , both of which formed the basis for our bias detection.

In Experiment 2, the absolute difference between test kits was analysed using an ANOVA appropriate for a split-plot design. The treatment structure was specified with fully factorial effects for Kit Type in full factorial combination with $\mathrm{pH}$ level. This was coded in GenStat as Kit Type*pH level. Assessor was specified as the blocking structure. Residual diagnostics performed in the analysis of Experiment 1 (phase A) were similarly performed here.

In all the ANOVA analyses (for Experiment 1 and 2), residual values were examined graphically to check for distributional normality and constant variance assumptions. Observations with standardised residuals greater than 3.0 were excluded from the analyses. The absolute difference data was square root transformed during analysis to establish normal distribution and constant variance. Least significant differences ( $5 \%$ level) were used to separate the means, subject to significant F-tests.

ANOVA analyses in Experiment 1 (phase A) and Experiment 2 were performed using the GenStat ${ }^{\circledR}$ statistical package (GenStat ${ }^{\circledR}$ Release 16.1, Copyright 2013, VSN International Ltd). The LM model was fitted using modified code based on a built-in LM function. The MLFR function was written based on the methodology described in Ripley and Thomson (1987). Both functions were implemented using the R statistical package (R Development Core Team 2015).

\section{Results}


258

259

260

261

262

263

264

265

A trellis plot of lab $\mathrm{pH}$ versus field $\mathrm{pH}$ is shown below in Figure 2. Each panel from A-J represents the information for each Assessor. In each panel, lab $\mathrm{pH}$ (x-axis) is plotted against field $\mathrm{pH}$ (y-axis) with least-squares lines fitted to the data. The fitted model is plotted against the 1:1 line (in red) with slope $=1$ and intercept $=0$ for comparison. The estimates for intercept and slope of the LM are printed in each panel, along with the estimated $R^{2}$. Each Assessor produced a different fit for the least-squares model with different intercept and slope estimates. This implies that there were different abilities between assessors to determine $\mathrm{pH}$ measurements in the field using a specific field $\mathrm{pH}$ kit.

A trellis plot of lab $\mathrm{pH}$ versus field $\mathrm{pH}$ (Figure 3), where the trellis is either Experienced (Yes) or Inexperienced (No), suggests that the two groups are different. The slope, intercept parameter and estimated $R^{2}$ were all different. This implies that a significant difference exists between the experienced and inexperienced Assessors in their ability to conduct soil $\mathrm{pH}$ measurements.

The ANOVA results showed that the main effects of Type $(\mathrm{P}<0.05)$ and $\mathrm{pH}$ Level $(\mathrm{P}<0.001)$ were significant but the interaction was not (Table 2). This implies that experienced Assessors were able to more accurately determine $\mathrm{pH}$ than inexperienced Assessors. The magnitude of error (getting the $\mathrm{pH}$ wrong) varied with $\mathrm{pH}$ level. It appeared that the degree of difficulties varies from one $\mathrm{pH}$ level to the next and this was consistent for all Assessors.

In phase $\mathrm{B}$ of Experiment 1, mean $\mathrm{pH}$ and corresponding measurement errors for all the samples using a laboratory $\mathrm{pH}$ meter and standard field technique ( $\mathrm{pH}$ kit) were averaged over all four groups then modelled using the MLFR and LM functions in R. Summary statistics are provided in Table 3. For the $\mathrm{LM}$, the intercept or $\alpha(1.214)$ is significantly $(\mathrm{P}<0.05)$ different from 0 ; the slope or $\beta(0.8064)$ is also significantly $(\mathrm{P}<0.01)$ different from 1 , signifying that there was a bias between lab $\mathrm{pH}$ and field $\mathrm{pH}$ in both the intercept and the slope. For MLFR, the intercept $(\alpha=0.342)$ was marginally $(\mathrm{P}<0.1)$ different from 0 and slope $(\beta=0.9341)$ was significantly $(\mathrm{P}<0.05)$ different from 1 . The MLFR result is much more conservative than the LM as the standard error of the parameter $(\alpha=0.182$ and standard error for $\beta$ (0.0269) are tighter (better estimated). However, both methods (MLFR and LM) showed that there 
was a bias between lab $\mathrm{pH}$ and field $\mathrm{pH}$. Figure 4 below shows that the LM (red line) and MLFR (green line) deviates from the 1:1 line (black). Both reveal bias with the LM biased at both extremes, whereas MLFR is biased at the high end only (indicating $\mathrm{pH}$ is more alkaline).

In the following analysis, all samples were split based on the combination of Assessor Type by timeof-day. The results of each combination are summarised in Table 4 and Figure 5. In Table 4, only statistics for the MLFR fit are presented as they are more robust. The MLFR parameter fits for the four scenarios of Assessor Type and Light quality showed that the slope and intercept parameters were biased. The LM fits are still shown in Figure 5 for comparison. Experienced assessors were positively biased at 1PM $(\alpha=0.7572)$ and 5PM $(\alpha=0.3477)$ with intercepts significantly different from 0 at $\mathrm{P}<0.01$. Inexperienced assessors were also biased at $1 \mathrm{PM}(\beta=1.5476)$ and $5 \mathrm{PM}(\beta=1.4273)$ with slopes also significantly different from 1 at $\mathrm{P}<0.01$.

\section{Experiment 2}

Two trellis plots are presented including field $\mathrm{pH}$ versus lab $\mathrm{pH}$ by Kit Type and Assessors (Figure 6), and field $\mathrm{pH}$ versus lab $\mathrm{pH}$ by Kit Type and Assessor Type (Figure 7). Each panel represents the information for each Assessor by Kit. The parameter ( $\alpha$ and $\beta$ ) estimates for each panel are different, indicating a significant effect of Kit and Assessor (experience) on the bias between field $\mathrm{pH}$ and lab $\mathrm{pH}$. The Assessor is the same as the panels in Figure 2.

Figure 6 showed that almost all fitted linear models were below the 1:1 line in the panels, indicating that field $\mathrm{pH}$ (measured by assessors) were almost always underestimating the lab $\mathrm{pH}$ (assumed to be the true $\mathrm{pH}$ ) and this was consistent for all assessors regardless of experience. For each Assessor, it is possible to compare between Kits using the paired panels. For example, panel 1 (Assessor A using Kit 1) can be compared with panel 2 (Assessor A using Kit 2). Similarly, panel 3 and 4 can be used to compare Assessor B using Kit 1 and 2 and so on. For each Assessor, a comparison between the fitted linear models to the 1:1 lines by Kit 1 and Kit 2 can be used to determine any potential difference between Assessors, Kits and their interactions. From this, we obtain the following summary: 
- Assessor A: performed better using Kit 2;

- Assessor B: no difference;

- Assessor C: no difference;

- Assessor D: performed better using Kit 2;

- Assessor F: performed better using Kit 2;

- Assessor G: performed better using Kit 2;

- Assessor H: no difference;

- Assessor I: no difference, and

- Assessor J: performed better using Kit 2.

In Figure 7 we can compare Kit 1 versus Kit 2 as well as Experienced (Yes) versus Inexperienced (No). Looking at all four panels, there was a difference between Kit 1 and Kit 2 where Kit 2 produced results that were closer to the lab results. This was consistent, regardless of the assessors' experience. Both Figures 6 and 7 indicate that there might be a significant difference between Kit and Assessor but no significant interaction between Assessor and Kit.

The ANOVA results (Table 5) identified that the main effects of Kit type $(\mathrm{P}<0.001)$ and $\mathrm{pH}$ Level $(\mathrm{P}<0.01)$ were significant but the interaction was not. The Kit type effect implied that using Kit 2, the assessors were able to obtain more accurate $\mathrm{pH}$ measurements than using Kit 1 . The magnitude of error (getting the $\mathrm{pH}$ wrong) varied with $\mathrm{pH}$ levels as in Experiment 1. The degree of difficulties varied from one $\mathrm{pH}$ level to the next and this was consistent for both kits (on the whole).

\section{Discussion}

\section{Assessor experience}

This study confirms that $\mathrm{pH}$ measured in the field has many potential sources of error, one of which is the experience of the user (Assessor). The experiments highlight that inexperienced field $\mathrm{pH}$ assessors 
under-perform against experienced assessors, and therefore a greater uncertainty, bias and error with field $\mathrm{pH}$ assessments can be expected from inexperienced assessors. This would suggest that for users with limited, or no previous experience using a field $\mathrm{pH}$ kit, there is likely to be greater error in the $\mathrm{pH}$ determination and therefore greater caution required when using these measurements for decision making, e.g. lime application. This does not account for spatial or temporal variability which are additional sources of uncertainty besides measurement error and epistemic error sources explored in the experimental design. From Experiment 1 to Experiment 2, there is the potential for those with limited to no experience to learn from others that participated in earlier assessments. This is akin to on-the-job training where junior or 'inexperienced' surveyors learn the field determination method under the guidance of an experienced operator with field $\mathrm{pH}$ determination. These findings suggest that introductory training and guidance from experienced users in the application of a field $\mathrm{pH}$ kit can be extremely beneficial to achieve accuracy and precision in $\mathrm{pH}$ determinations. Ongoing quality assurance and control should also be considered as part of regular testing regimes for persons measuring field $\mathrm{pH}$.

While differences between the two assessor groups were evident, there was no clear relationship between the $\mathrm{pH}$ level of assessment and the assessor group across the $\mathrm{pH}$ range of this study. There were $\mathrm{pH}$ levels that were more difficult to assess than others such as $\mathrm{pH}$ levels 6.5 and 10 . The experiment reveals that the differences in performance are most likely due to the interpretation of the colour card at these $\mathrm{pH}$ values rather than the quality or age of the indicator solution or barium sulphate.

There are difficulties in interpretation of the colour graduation on the cards, especially for males which have a deficiency in the red/green region (as evident in results from the Ishihara colour chart). In collated soil site information from soil and land surveys in Victoria contained in the VSIS, there are 51 reported surveyors that have participated in studies where field $\mathrm{pH}$ observations have been collected for 3398 sites. Of the 51 surveyors, only $20 \%$ are female. It is unclear how many of the surveyors were properly assessed for vision impairment or were adequately trained for field $\mathrm{pH}$ determination, although, often in the field surveyors would cross-reference with one another especially if uncertain on the $\mathrm{pH}$ assignment class. 
All participants in this study demonstrated different abilities to predict $\mathrm{pH}$ using the field determination method. This was reflected in the different bias, error and model fit for every assessor. As there is bias represented in the LM and MLFR models between field $\mathrm{pH}$ and lab $\mathrm{pH}$, there is a need for users of such assessments to be prudent as field $\mathrm{pH}$ results in this study do not agree perfectly with $\mathrm{pH}$ data measured in the laboratory. While both the LM and MLFR display a bias between lab $\mathrm{pH}$ and field $\mathrm{pH}$, the MLFR provides a much improved fit than the LM which is biased at both high and low $\mathrm{pH}$ values, whereas the MLFR is biased only for high $\mathrm{pH}$ values. Further improvements of the MLFR over the LM are evident where the standard error of the model parameters is considerably less than those of the LM.

Baker et al. (1983) and Steinhardt and Mengel (1981) have established quite different results for bias in the relationship between field and laboratory $\mathrm{pH}$ measurements. This study also achieved systematic differences (bias) for the different assessors and assessor groups. Strong agreement between field $\mathrm{pH}$ and lab $\mathrm{pH}$ has been found where one experienced assessor completes all field $\mathrm{pH}$ assessments (Baker et al. 1983). From our study the samples were specifically chosen to represent the spread of pH levels represented in the colour cards, but also variations in soil properties such as colour, depth, clay $\%$ and organic carbon content that may contribute to error in measurement. This provides a degree of confidence in the agreement between methods being maintained for a significantly larger sample size. It is unclear, and beyond the scope of this evaluation, if soil colour made a difference to perception of pH level.

\section{Time-of-day (light quality)}

Another potential source of uncertainty in field determination of $\mathrm{pH}$ is the quality of light. Although this study did not formally test light quality, as we were unable to randomise time in our experimental design, we did assess, using a LM and MLFR, if there were differences between two different times of 
day that were intended to represent good quality and poor quality light. The results demonstrated that with measurement errors for both the lab $\mathrm{pH}$ and field $\mathrm{pH}$, we were able to detect bias in the slopes and intercepts for the four scenarios of time-of-day and assessor group. The MLFR model for the experienced assessor group was better than the inexperienced for 1PM and 5PM. Observation time was not a significant factor for both experienced and inexperienced assessor groups. This is not surprising given that light quality (brightness and glare) for the two times of day of the experiment (1PM and 5PM) was relatively similar. Glare as a light quality factor was noted as an issue in $\mathrm{pH}$ assessment by assessors of both groups. On the first day (Experiment 1), the light quality at 5PM was considered as good, if not better than the light quality at 1PM. In our pre-experiment design, we had expected that light quality later in the day would be poorer, but this effect was not observed. It is expected that light quality will be a significant factor for both experienced and inexperienced assessors in future experiments, if we can replicate and quantify true "good" and "poor" light quality in our design.

\section{Kit type differences}

A final source of uncertainty considered in this study was difference between commercially available field colorimetric indicator $\mathrm{pH}$ kits. Both kits used in this study resulted in underestimated lab $\mathrm{pH}$ for all assessors. There were consistently better results achieved for all assessors regardless of experience for Kit 2 in comparison with Kit 1 . The $\mathrm{pH}$ levels differences between the kits were inconsistent although there were some $\mathrm{pH}$ levels (e.g. 7.5) that had an absolute difference between the two kits close to 1 . This could potentially be due to a number of error sources including indictor and $\mathrm{BaSO}_{4}$ impurities or slight differences that were apparent in the colour cards for the two kits. This requires further investigation as users of field $\mathrm{pH}$ kits need confidence in the ability to easily contrast the treated sample with colours represented on the indicator card.

The comparison of kits has highlighted that it is prudent to remove kit type error as a potential source and use one kit type only. Batch to batch variation in kits is potentially a substantial source of error, especially where impurities exist in solvents and reagents, but this was not able to be factored into the experimental design for this study. 
Field $\mathrm{pH}$ measurements have been used for soil survey and agricultural advisory work for over 60 years, highlighting the robustness, simplicity and reliability of the procedure. Field determination of soil $\mathrm{pH}$ using the Raupach and Tucker (1959) procedure can produce reliable results in comparison to laboratory $\mathrm{pH}$. In particular, field $\mathrm{pH}$ determination has provided a role in the screening of samples for potential laboratory analysis, should it be required. A benefit of the current field $\mathrm{pH}$ method is that there has been no change to the methodology and chemical constituents since its conception. In contrast, modifications to laboratory techniques over the last 60 -years including stirring effects and operator differences are likely to represent sources of uncertainty in legacy $\mathrm{pH}$ data greater than currently reported values, e.g. $\pm 0.1 \mathrm{pH}$ unit. This suggests that as a method for determining soil reaction, it has been an adequate servant for many soil mapping activities over this period.

In the absence of representative laboratory measurements, there is little evidence to suspect that field determinations with greater uncertainty cannot serve as useful replacements for laboratory measurements in spatial and temporal assessments for mapping and monitoring purposes. The findings from this study support the wider use of legacy field $\mathrm{pH}$ data for soil mapping purposes at regional to national scales. A mapping technique that could utilise legacy field $\mathrm{pH}$ observations in partnership with lab pH is a linear model of coregionalization (LMCR; Webster and Oliver 2001) using a model-thencalculate, or, calculate-then-model approach described by Orton et al. (2014).

The two experiments reported in this study provide an account of error sources that add to field $\mathrm{pH}$ uncertainty. By understanding the nature and magnitude of these errors, we can determine and understand the error bounds represented by the confidence and prediction intervals and provide information on error propagation in mapping and modelling applications. Further investigation to understand the errors in soil survey should be considered to screen legacy soil $\mathrm{pH}$ observations prior to use in regional monitoring or mapping applications. The differences found between experienced and inexperienced operators of field $\mathrm{pH}$ kits can also be used to guide cleansing of field $\mathrm{pH}$ from various sources, such as data from citizen science and crowd sourcing (Rossiter et al. 2015). 
440 Other factors unaccounted for in explaining differences between field and laboratory $\mathrm{pH}$ include 441 oxidation effects due to soil storage conditions (Slattery and Burnett 1992) and incorporation of 442 pedogenic segregations (e.g. calcareous) into the $<2 \mathrm{~mm}$ fraction through differences in sample 443 preparation procedures.

444 While dealing with legacy data can be problematic due to insufficient metadata to isolate effects due to operator experience, test kit differences and light quality characteristics at time of observation, this should not preclude the capture of new error sources in future. Practical suggestions to increase the certainty in field $\mathrm{pH}$ data include: a level of training to provide assessor certification across the soil $\mathrm{pH}$ range; field kits should be regularly tested against known standards, and the test kit should be identified in metadata associated with field measurements. Also to be noted are date and time of observation recorded, and assessor and other factors that may contribute to potential significant differences between field and laboratory measurements (e.g. soil moisture status, observed segregations, depth). An important consideration when assessing $\mathrm{pH}$ in the field or laboratory, or producing maps for planning and land use decision-making, is what is the intended use or purpose of the data. While high precision and accuracy is generally useful, it is often the critical $\mathrm{pH}$ ranges relevant to management (e.g. effect plant production, nitrate leaching into groundwater and waterways or corrosion of infrastructure) that are sought. Using the diagnostic $\mathrm{pH}$ ranges described by Slattery et al. (1999) as a guide, the critical range of 5.3 to 5.8 is where accurate measurements are most valuable due to the sensitivity of grain and pasture cultivars from the effects of exchangeable manganese and aluminium at these levels. Below this threshold there are implicit and known significant impacts to plant production where remediation actions are necessary. But is high accuracy and precision required here? Likewise, above a $\mathrm{pH}$ of 5.8, there are few limitations except where trace elements such as zinc and molybdenum are less available to plants at $\mathrm{pH}$ values of 8 and above. Unpublished investigations by the authors identify interquartile range (IQR) values for field $\mathrm{pH}$ values 5, 5.5 and 6 against laboratory measurement as 4.9-5.5, 5.1-5.6 and 5.4-6.1. These IQRs suggest that field $\mathrm{pH}$ determinations around this diagnostic range are more than just useful indicators especially given that the amount of agricultural land to have $\mathrm{pH}$ values in this $\mathrm{pH}$ range or below was expected to double to 43-64 million hectares in the coming decade (Dolling et al. 2001). 
Field $\mathrm{pH}$ is a useful indicator of soil condition and has practical value for soil pre-screening and rapid classification. Field observations may have additional utility in soil mapping where there is insufficient

472 data available from laboratory $\mathrm{pH}$ determinations. While field $\mathrm{pH}$ determinations are not as accurate as laboratory measurements, they do provide valuable support for laboratory measurements that are spatially and temporally sparse or biased. This evaluation study of field $\mathrm{pH}$ test kits has demonstrated that user experience with a $\mathrm{pH}$ test kit will have an impact on the prediction accuracy and uncertainty. This study also confirmed that sources of uncertainty in field $\mathrm{pH}$ assessments, such as choice of kit, will affect the accuracy and bias of $\mathrm{pH}$ determination in comparison to laboratory measurements.

478 Using the field colorimetric method, some $\mathrm{pH}$ levels at the extreme range were more difficult to determine than others, regardless of assessor experience. There is likely to be bias between field and laboratory measurements and there are distinct benefits from using a kit free from impurities and with a colour card that is consistent with colours expressed in treated samples. Mixing of commercial kits when attempting to harmonise legacy measurements because of differences between the kits may introduce additional uncertainty. The experimental methodology implemented for this study could be modified to accommodate further test subjects and potential error sources, such as within-kit and between-kit variability, or to consider spatial and temporal variability as additional factors. It is recommended that further investigation is pursued on the possible effects of sample size and gender on test kit performance and reliability.

\section{Acknowledgements}

The authors acknowledge the support of the Land Knowledge Foundations Project through the

491 Victorian Department of Economic Development, Jobs, Transport and Resources. We would 492 particularly wish to thank Kerry Stott, Ivanah Oliver, Matt Kitching, Mark Imhof, Lucy Finger, Christie Ho for volunteering for this experiment, and Doug Crawford for his insightful comments on this manuscript. 


\section{References}

Baker, D.E., G.E. Rayment, and R.E. Reid. 1983. Predictive relationships between pH and sodicity in soils of tropical Queensland. Communications in Soil Science and Plant Analysis 14(11):1063-1073.

Benke, K.K., D.R. Skinner, and C.J. Woodruff. 1988. Convolution operators as a basis for objective correlates of texture perception. IEEE Transactions on Systems, Man, and Cybernetics 18(1):158-163.

Carré, F., A.B. McBratney, T. Mayr, and L. Montanarella. 2007. Digital Soil assessments: beyond DSM. Geoderma 142:69-79.

Dixon, E.R. 1978. Spectral distribution of Australian daylight. Journal of the Optical Society of America 68:437-450. https://doi.org/10.1364/JOSA.68.000437.

Dolling, P.J., P. Moody, A. Noble, K. Helyar, B. Hughes, D. Reuter, and L. Sparrow. 2001. Soil Acidity and Acidification. Final report to National Land and Water Resources Audit for Project 5.4C. Canberra: National Land and Water Resources Audit.

de Caritat, P., M. Cooper, and J. Wilford. 2011. The pH of Australian soils: field results from a national survey. Soil Research 49(2):173-182. http://dx.doi.org/10.1071/SR10121.

Farnsworth, D. 1943. The Farnsworth-Munsell 100-Hue and Dichotomous Tests for Color Vision. Journal of the Optical Society of America 33:568-574. https://doi.org/10.1364/JOSA.33.000568.

Hopley, J., D.B. Rees, R.J. MacEwan, R. Clark, K. Benke, M.P. Imhof, N.J. Robinson, and D.C. Bardos. 2014. A digital soil map of Victoria_VicDSMv1. In GlobalSoilMap: Basis of the global spatial soil information system, eds. D. Arrouays, N. McKenzie, J. Hempel, A.R. de Forges, A.B. McBratney, 185-190. London: CRC Press.

Hunter, D., S. Williams, and N. Robinson. 2010. VSIS an new system for Victorian soil data. In Proceedings 19th World Congress of Soil Science, Brisbane, Australia: Soil Solutions for a 

Soil Sciences.

Isbell, R.F. 2002. The Australian Soil Classification. Revised Edition. Melbourne: CSIRO Publishing.

Laslett, G., and A.B. McBratney. 1990. Estimation and implications of instrument drift, random measurement error and nugget variance of soil attributes-a case study for soil pH. Journal of Soil Science 41:451-471.

McBratney, A.B., M.L. Mendonça Santos, and B. Minasny. 2003. On digital soil mapping. Geoderma

National Committee on Soil and Terrain. 2009. Australian Soil and Land Survey Field Handbook, $3^{\text {rd }}$ ed. Melbourne: CSIRO Publishing.

Mason, D., and S. Obenshain. 1939. A Comparison of Methods for the Determination of Soil Reaction. Soil Science Society of America Journal 3:129 -137. doi:10.2136/sssaj1939.036159950003000c0027x. $117: 3-52$.

Orton, T.G., M.J. Pringle, K.L. Page, R.C. Dalal, and T.F.A. Bishop. 2014. Spatial prediction of soil organic carbon stock using a linear model of coregionalisation. Geoderma 230-231:119-130.

R Development Core Team. 2015. R: A language and environment for statistical computing, R version 3.1.3. R Foundation for Statistical Computing, Vienna, Austria. ISBN 3-900051-070, www.R-project.org/.

Raupach, M. 1950. An indicator outfit for soil reaction tests in the field. Journal of the Australian Institute of Agricultural Science 16:108.

Raupach, M., and B.M. Tucker. 1959. The field determination of soil reaction. Journal of the Australian Institute of Agricultural Science 25(2):129-133.

Rayment, G.E., and D.J. Lyons. 2011. Soil chemical methods: Australasia, Vol. 3. Melbourne: CSIRO Publishing.

Ripley, B.D., and M. Thompson. 1987. Regression techniques for the detection of analytical bias. Analyst 112:377-383.

Rossiter, D.G., J. Liu, S. Carlisle, and A.X. Zhu. 2015. Can citizen science assist digital soil mapping? Geoderma 259-260:71-80. 
549 Sarkar, D. 2008. Lattice: Multivariate Data Visualization with R. New York: Springer-Verlag.

550 Slattery, W.J., and V.F. Burnett. 1992. Changes in soil pH due to long term soil storage. Australian $551 \quad$ Journal of Soil Research 30(2):169-175.

552 Slattery, W.J., M.K. Conyers, and R.L. Aitken. 1999. Soil pH, aluminium, manganese and lime 553 requirement. In Soil analysis, an interpretation manual, eds K.I. Peverill, L.A. Sparrow, D.J. Reuter, 103-128. Melbourne: CSIRO Publishing.

555

556

557

558

559

560

561

562

563

564 Science 35:3-14. 
1
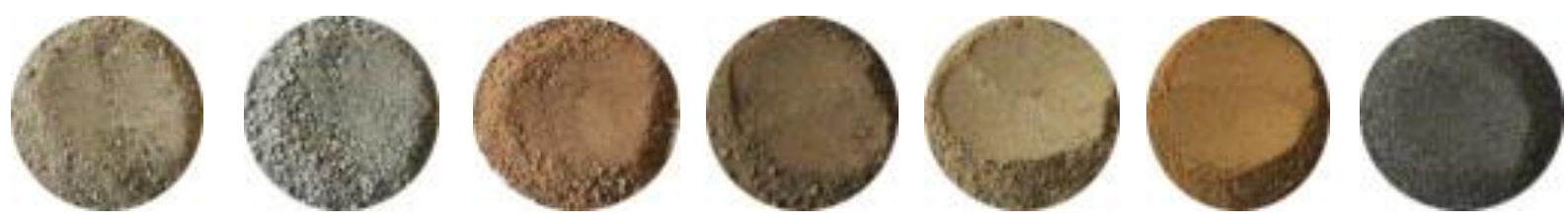

4.5

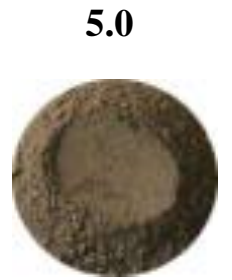

5.5

5.5

6.5

7.0

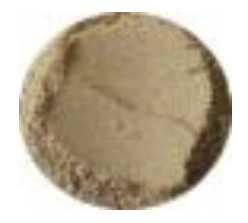

7.5

8.0

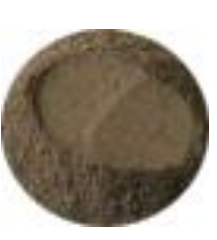

8.5

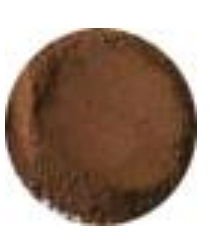

9.0

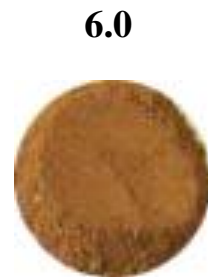

9.5

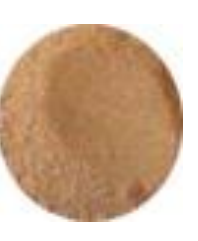

10.0

2 Figure 1 Samples used in experiments with $\mathrm{pH}$ level 


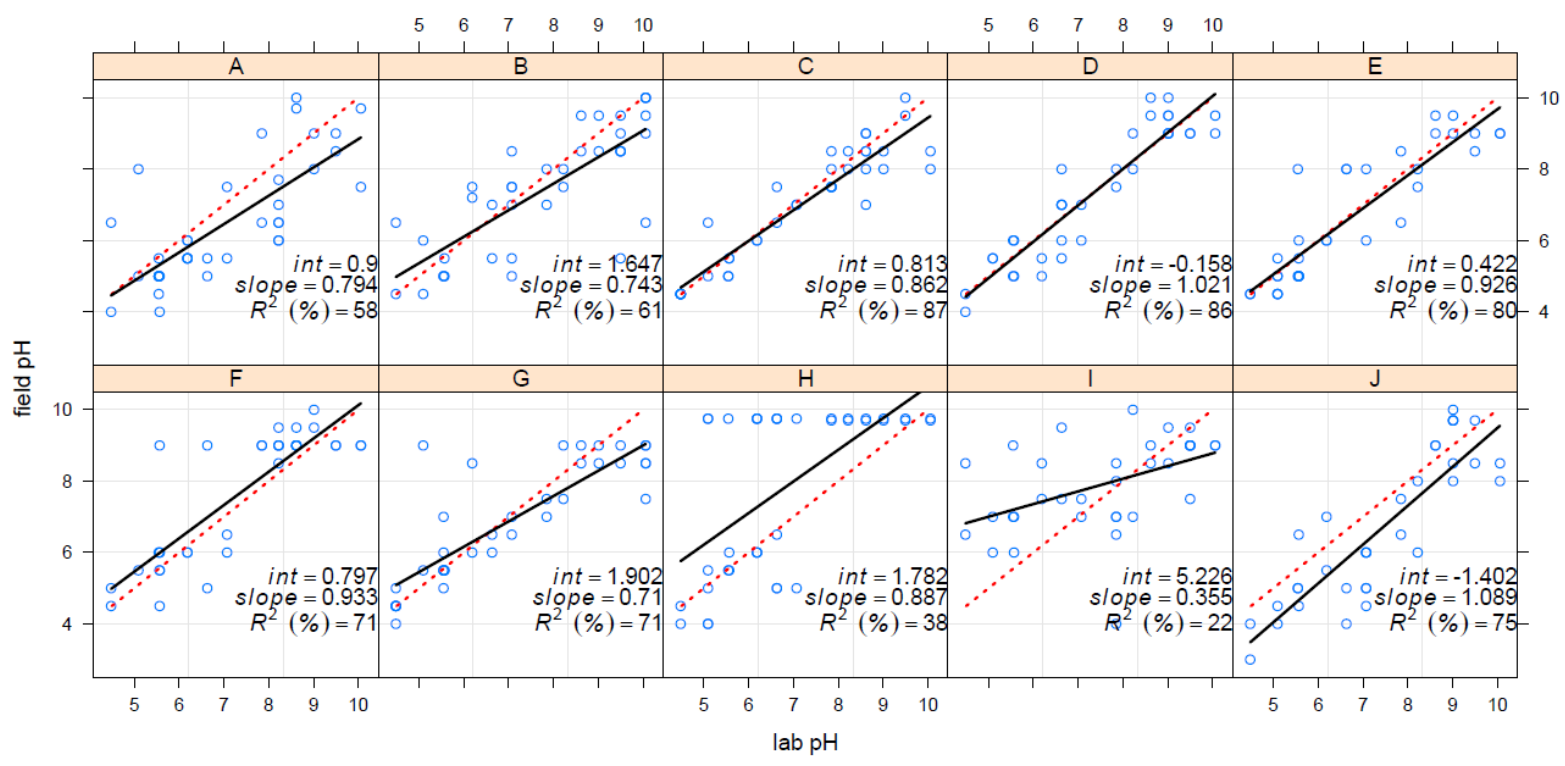

5

Figure 2 Trellis plot of field $\mathrm{pH}$ versus lab $\mathrm{pH}$ by Assessor. The red dashed line is the 1:1 line.

6

7 


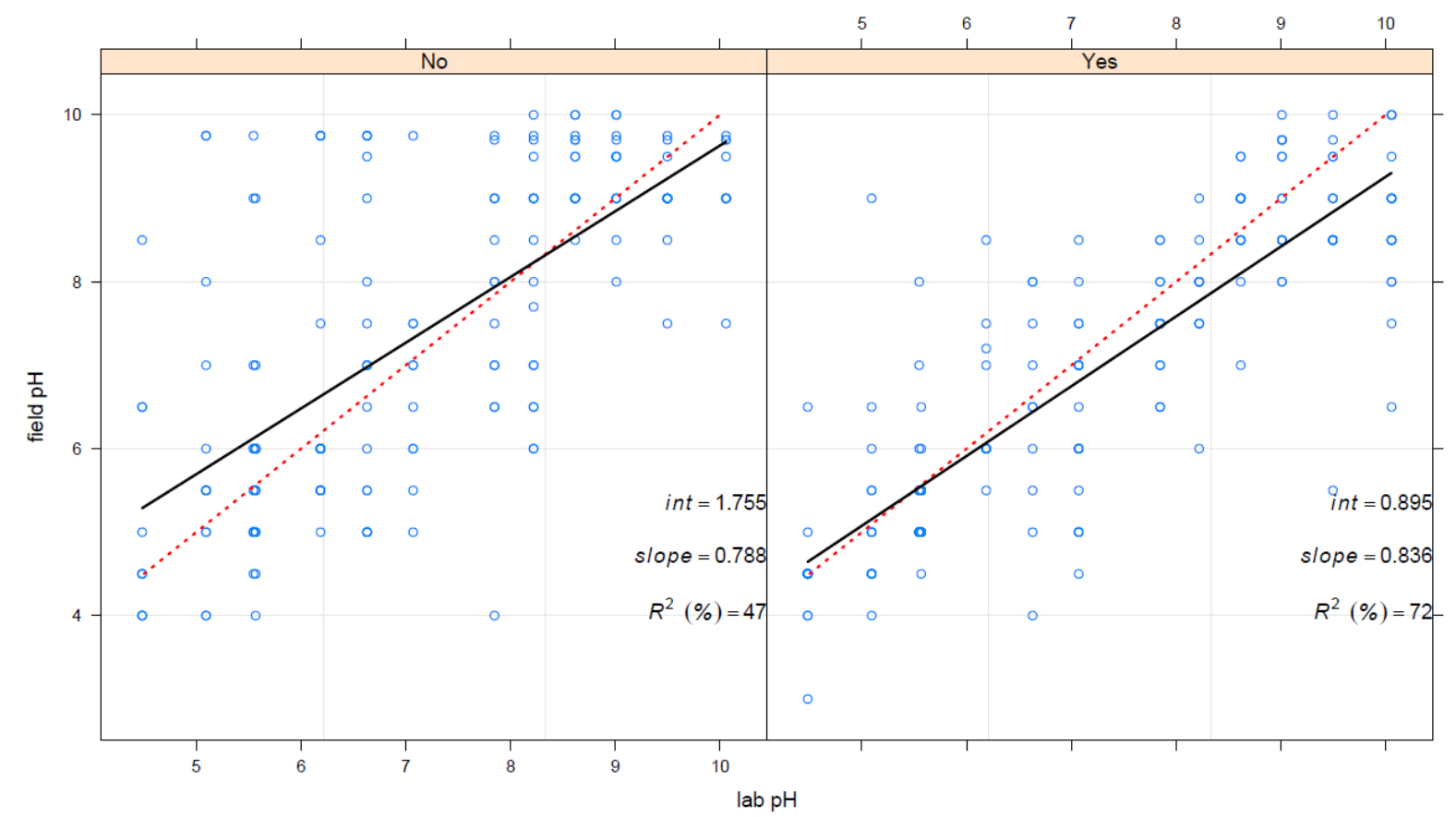

10 Figure 3 Trellis plot of field $\mathrm{pH}$ versus lab $\mathrm{pH}$ by Experience. The red dashed line is the 1:1 line.

11

12 


\section{Averaged over all four groups}

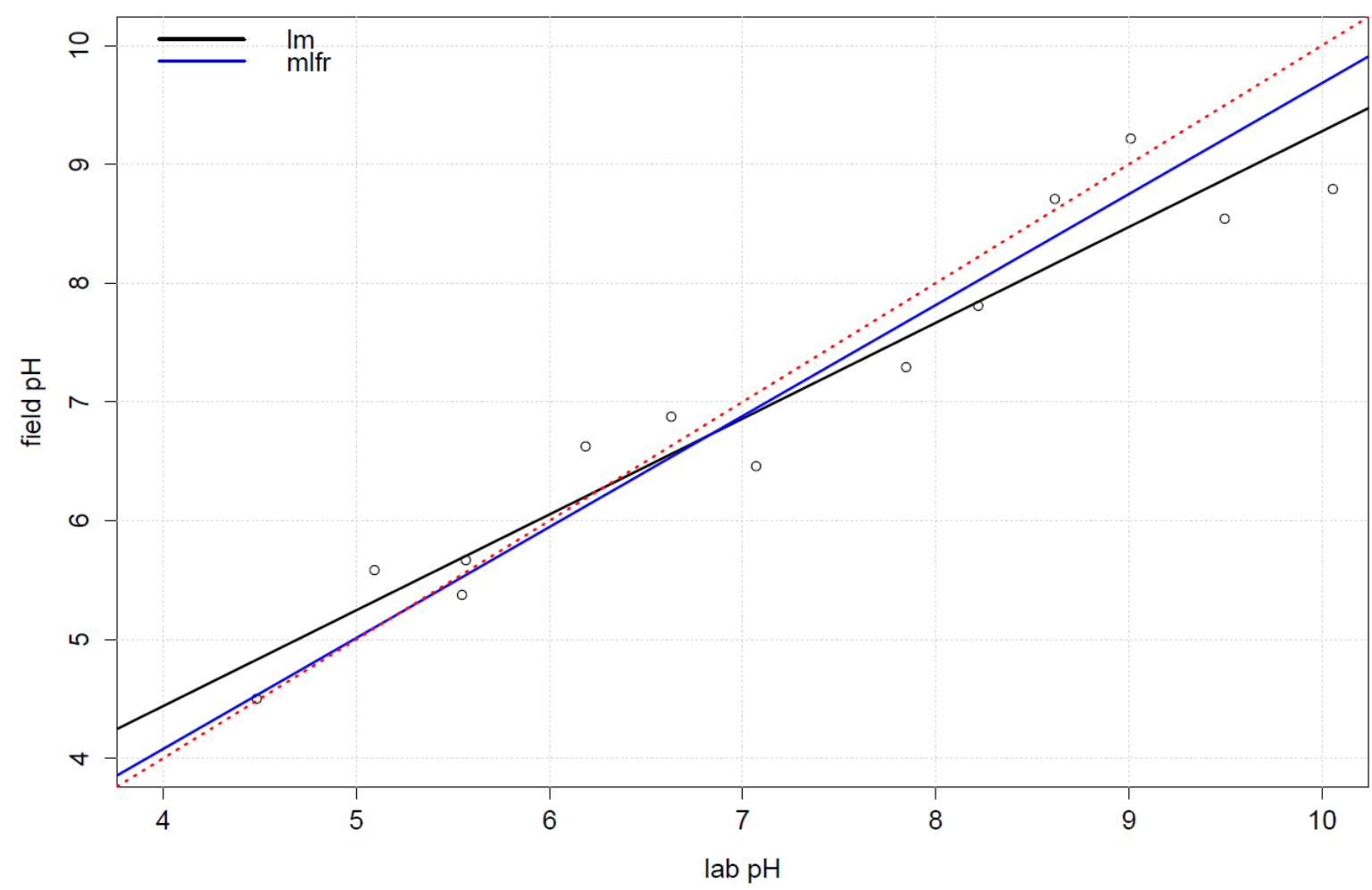

13

14 Figure 4 Field $\mathrm{pH}$ versus lab $\mathrm{pH}$ with fitted models using LM (black line) and MLFR (blue line). The 15 red dashed line is the $1: 1$ line. 


\section{Experienced and $1 \mathrm{PM}$}

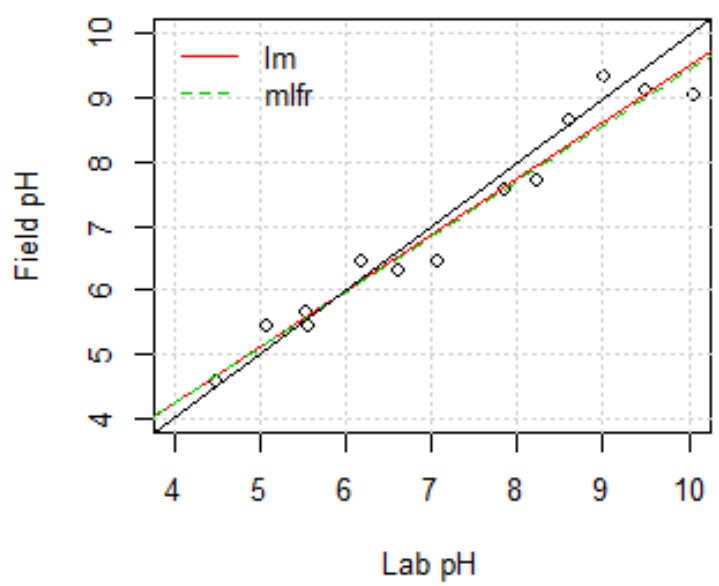

Inexperienced and $1 \mathrm{PM}$

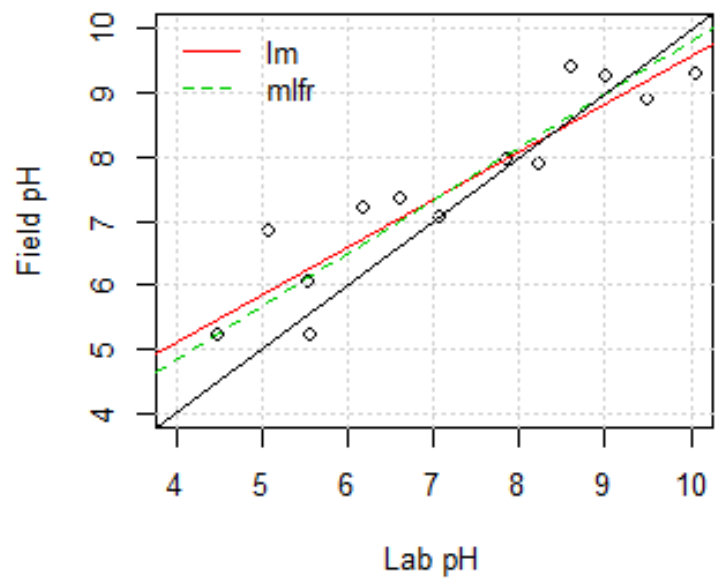

Experienced and $5 \mathrm{PM}$

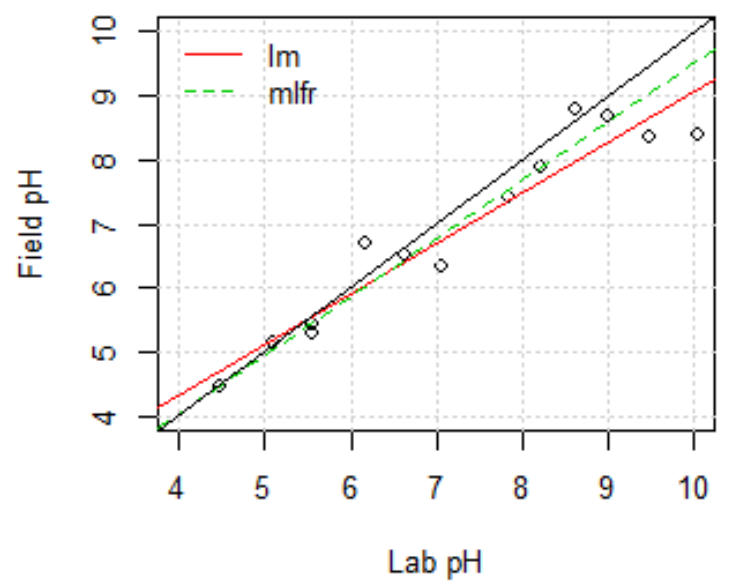

Inexperienced and $5 \mathrm{PM}$

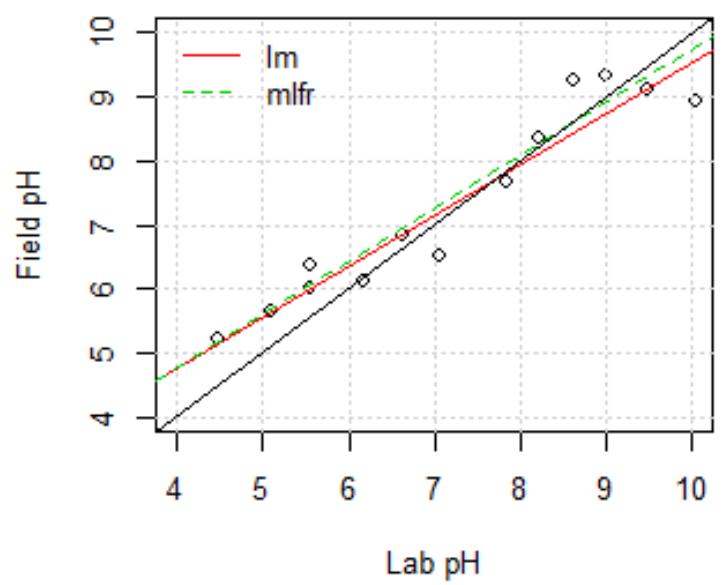

17

18 Figure 5 Field $\mathrm{pH}$ versus lab $\mathrm{pH}$ for the four different scenarios - (Case 1) Experienced and 1PM (top 19 left-hand corner), (Case 2) Experienced and 5PM (top right-hand corner), (3) Inexperienced and 1PM 20 (bottom left-hand corner) and (4) Inexperienced and 5PM (bottom right-hand corner). The black line 21 is the 1:1 line. 


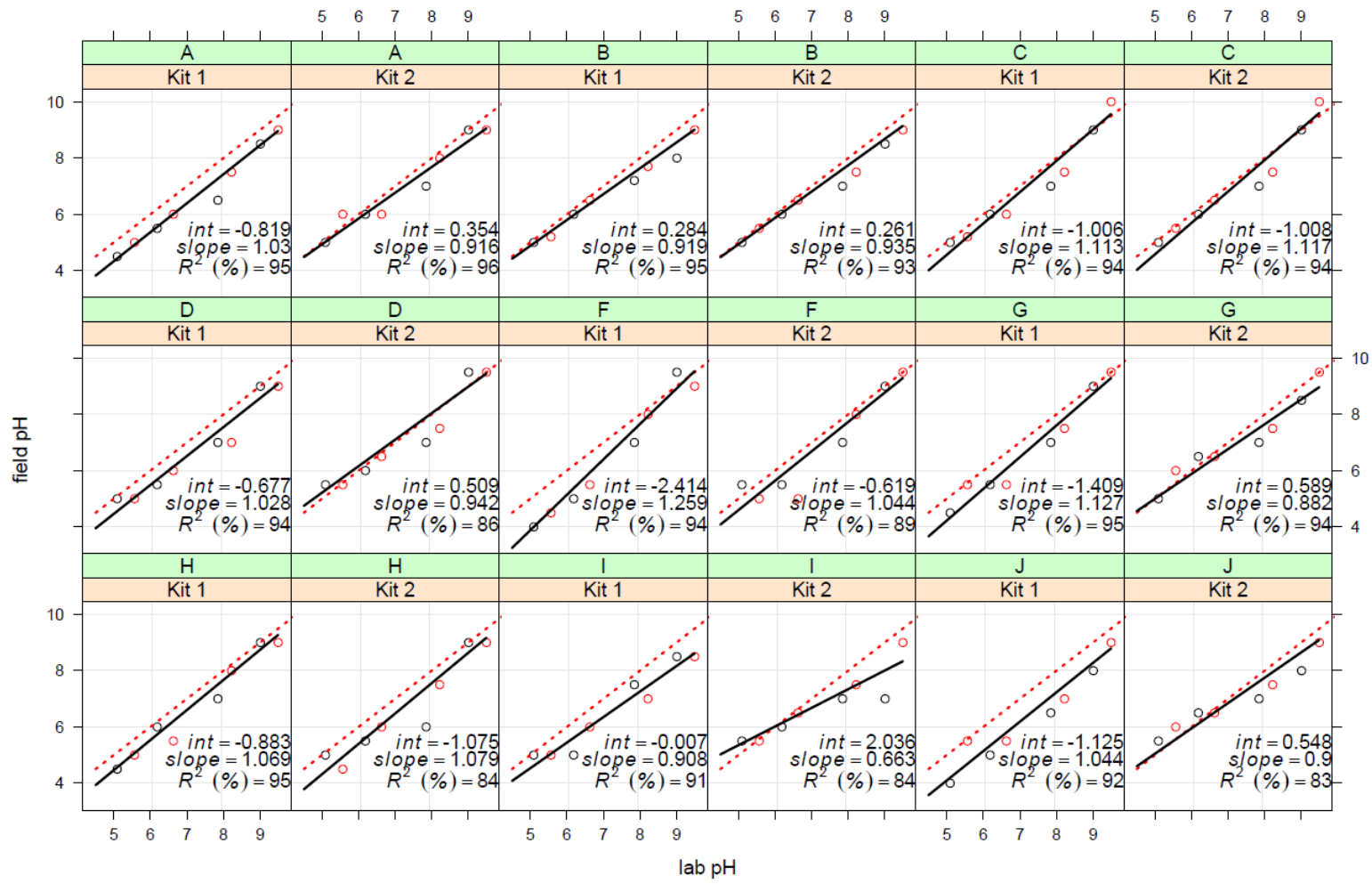

Figure 6 Trellis plots of field $\mathrm{pH}$ versus lab $\mathrm{pH}$ by Kit by Assessor. 


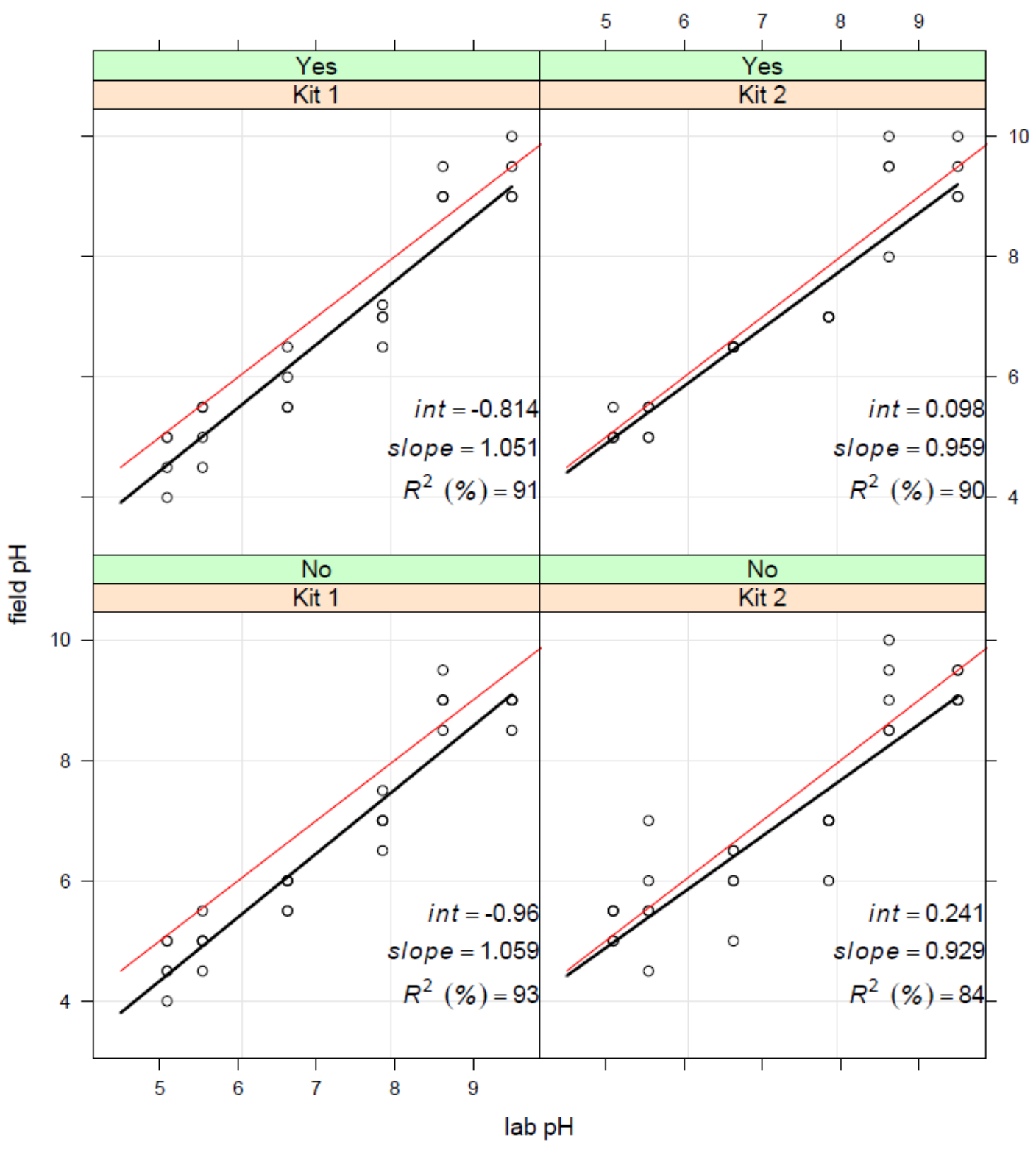

27

28 Figure 7 Trellis plot of field $\mathrm{pH}$ versus lab $\mathrm{pH}$ for Kit by Assessor Type. 
Table 1 Site, sampled depth, ASC order and soil properties

\begin{tabular}{lccccc}
\hline Site & $\begin{array}{c}\text { ASC } \\
\text { (Isbell } \\
2002)\end{array}$ & $\begin{array}{c}\text { Depth } \\
(\mathrm{cm})\end{array}$ & ${\text { Clay } \%^{1}}$ & E.C. (dS/m) ${ }^{2}$ & Org. C \% $^{3}$ \\
\hline USFS_VP100 & CH & $10-20$ & 33 & 0.06 & \\
USFS_VP11 & SO & $0-10$ & 21 & 0.10 & 1.65 \\
USFS_VP32 & SO & $0-10$ & 23 & 0.15 & 2.30 \\
USFS_VP36 & CH & $80-90$ & 51 & 0.18 & 0.55 \\
USFS_VP38 & SO & $40-50$ & 49 & 0.17 & 0.74 \\
USFS_VP5 & CH & $90-100$ & 86 & 0.13 & 0.37 \\
USFS_VP66 & CH & $0-10$ & 22 & 0.12 & 2.78 \\
USFS_VP71 & CH & $90-100$ & 34 & 0.09 & 0.38 \\
USFS_VW150 & CA & $60-70$ & 53 & 2.43 & 0.28 \\
USFS_VW55 & CA & $80-90$ & 28 & 0.72 & 0.53 \\
CSMP_89_C1 & DE & $38-75$ & 41 & 0.26 & 10.05 \\
CSMP_100_C1 & VE & $69-92$ & 34 & 0.87 & 3.07 \\
SW22 & DE & $5-25$ & 10 & 0.14 & 9.60 \\
\hline
\end{tabular}

31

${ }^{1}$ From laboratory or Mid-Infra-Red (MIR) prediction

${ }^{2}$ Method 3A1 from Rayment and Lyons (2011)

${ }^{3}$ Method 6B3 or 6B4 from Rayment and Lyons (2011) 
36 Table 2 ANOVA for the absolute difference between lab $\mathrm{pH}$ and field $\mathrm{pH}$ with two types of assessors 37 and thirteen levels of $\mathrm{pH}$. Mean values (back-transformed mean) are presented.

\begin{tabular}{ll}
\hline Factor & Absolute difference \\
\hline Type of Assessors & \\
Experienced & $0.75(0.56)$ \\
Inexperienced & $0.90(0.81)$ \\
LSD $(5 \%)$ & 0.14 \\
pH Levels & \\
& \\
4.5 & 0.61 \\
5.0 & 0.83 \\
5.5 & 0.73 \\
5.5 & 0.85 \\
6.0 & 0.85 \\
6.5 & 1.08 \\
7.0 & 0.80 \\
7.5 & 0.88 \\
8.0 & 0.86 \\
8.5 & 0.77 \\
9.0 & 0.70 \\
9.5 & 0.66 \\
10.0 & 1.12 \\
LSD $(5 \%)$ & 0.24 \\
& \\
F-test probabilities & 0.03 \\
Types of Assessor (T) & \\
pHels (L) & \\
&
\end{tabular}


40 Table 3 Summary of LM and MLFR model parameters between $\mathrm{pH}$ data measured in the field (from 41 our experiment) as the response variable (y) and $\mathrm{pH}$ data measured in the laboratory as the fixed 42 variable $(\mathrm{x})$.

\begin{tabular}{lcc}
\hline & LM & MLFR \\
\hline Intercept $(\alpha)$ & 1.2137 & 0.3424 \\
Standard error of Intercept (s.e $(\alpha))$ & 0.5156 & 0.1820 \\
Probability $\alpha \neq 0$ & 0.0186 & 0.0599 \\
Slope $(\beta)$ & 0.8064 & 0.9341 \\
Standard error of Intercept (s.e( $\beta))$ & 0.0695 & 0.0269 \\
Probability $\beta \neq 1$ & 0.0053 & 0.0142 \\
\hline
\end{tabular}

43

44 
45 Table 4 Summary of MLFR model parameters for field $\mathrm{pH}(\mathrm{y})$ and lab $\mathrm{pH}$ data (x) for four scenarios:

46 (Case 1) Experienced and 1PM, (Case 2) Experienced and 5PM, (3) Inexperienced and 1PM and (4) 47 Inexperienced and 5PM.

\begin{tabular}{lcccc}
\hline & Case 1 & Case 2 & Case 3 & Case 4 \\
\hline Intercept $(\alpha)$ & 0.7572 & 0.3477 & 1.5476 & 1.4273 \\
Standard error of Intercept (s.e $(\alpha))$ & 0.3393 & 0.2381 & 0.5273 & 0.4933 \\
Probability $\alpha \neq 0$ & 0.0257 & 0.1443 & 0.0033 & 0.0038 \\
Slope $(\beta)$ & 0.8705 & 0.9178 & 0.8256 & 0.8315 \\
Standard error of Intercept (s.e( $\beta))$ & 0.0430 & 0.0347 & 0.0604 & 0.0580 \\
Probability $\beta \neq 1$ & 0.0026 & 0.0177 & 0.0039 & 0.0037 \\
\hline
\end{tabular}

48

49 
50 Table 5 ANOVA for the absolute difference between lab $\mathrm{pH}$ and field $\mathrm{pH}$ with two kits and twelve 51 levels of $\mathrm{pH}$. Mean values are presented.

\begin{tabular}{|c|c|}
\hline Factor & Absolute difference \\
\hline \multicolumn{2}{|l|}{ Kit Type } \\
\hline Kit 1 & 0.603 \\
\hline Kit 2 & 0.473 \\
\hline $\operatorname{LSD}(5 \%)$ & 0.0924 \\
\hline \multicolumn{2}{|l|}{ pH Levels } \\
\hline 4.5 & 0.372 \\
\hline 5.0 & 0.357 \\
\hline 5.5 & 0.411 \\
\hline 5.5 & 0.481 \\
\hline 6.0 & 0.506 \\
\hline 6.5 & 0.602 \\
\hline 7.0 & 0.653 \\
\hline 7.5 & 0.919 \\
\hline 8.0 & 0.681 \\
\hline 8.5 & 0.602 \\
\hline 9.0 & 0.452 \\
\hline 9.5 & 0.473 \\
\hline $\operatorname{LSD}(5 \%)$ & 0.2532 \\
\hline \multicolumn{2}{|l|}{ F-test probabilities } \\
\hline Types of Kits (K) & 0.006 \\
\hline pH Levels (L) & $<0.001$ \\
\hline
\end{tabular}

52 
Table 1 Site, sampled depth, ASC order and soil properties

\begin{tabular}{lccccc}
\hline Site & $\begin{array}{c}\text { ASC } \\
\text { (Isbell } \\
2002)\end{array}$ & $\begin{array}{c}\text { Depth } \\
(\mathrm{cm})\end{array}$ & ${\text { Clay } \%^{1}}$ & E.C. (dS/m) ${ }^{2}$ & Org. C \% $^{3}$ \\
& CH & $10-20$ & 33 & 0.06 & \\
\hline USFS_VP100 & SO & $0-10$ & 21 & 0.10 & 2.65 \\
USFS_VP11 & SO & $0-10$ & 23 & 0.15 & 2.97 \\
USFS_VP32 & CH & $80-90$ & 51 & 0.18 & 0.55 \\
USFS_VP36 & SO & $40-50$ & 49 & 0.17 & 0.74 \\
USFS_VP38 & CH & $90-100$ & 86 & 0.13 & 0.37 \\
USFS_VP5 & CH & $0-10$ & 22 & 0.12 & 2.78 \\
USFS_VP66 & CH & $90-100$ & 34 & 0.09 & 0.38 \\
USFS_VP71 & CA & $60-70$ & 53 & 2.43 & 0.28 \\
USFS_VW150 & CA & $80-90$ & 28 & 0.72 & 0.53 \\
USFS_VW55 & DE & $38-75$ & 41 & 0.26 & 10.05 \\
CSMP_89_C1 & VE & $69-92$ & 34 & 0.87 & 3.07 \\
CSMP_100_C1 & DE & $5-25$ & 10 & 0.14 & 9.60 \\
SW22 & & & & \\
\hline
\end{tabular}

${ }^{1}$ From laboratory or Mid-Infra-Red (MIR) prediction

${ }^{2}$ Method 3A1 from Rayment and Lyons (2011)

${ }^{3}$ Method 6B3 or 6B4 from Rayment and Lyons (2011) 
7 Table 2 ANOVA for the absolute difference between lab $\mathrm{pH}$ and field $\mathrm{pH}$ with two types of assessors 8 and thirteen levels of $\mathrm{pH}$. Mean values (back-transformed mean) are presented.

\begin{tabular}{ll}
\hline Factor & Absolute difference \\
\hline Type of Assessors & \\
Experienced & $0.75(0.56)$ \\
Inexperienced & $0.90(0.81)$ \\
LSD $(5 \%)$ & 0.14 \\
pH Levels & \\
& \\
4.5 & 0.61 \\
5.0 & 0.83 \\
5.5 & 0.73 \\
5.5 & 0.85 \\
6.0 & 0.85 \\
6.5 & 1.08 \\
7.0 & 0.80 \\
7.5 & 0.88 \\
8.0 & 0.86 \\
8.5 & 0.77 \\
9.0 & 0.70 \\
9.5 & 0.66 \\
10.0 & 1.12 \\
LSD $(5 \%)$ & 0.24 \\
& \\
F-test probabilities & 0.03 \\
Types of Assessor (T) & \\
pHels (L) & \\
&
\end{tabular}

9

10 
11 Table 3 Summary of LM and MLFR model parameters between $\mathrm{pH}$ data measured in the field (from 12 our experiment) as the response variable (y) and $\mathrm{pH}$ data measured in the laboratory as the fixed 13 variable $(\mathrm{x})$.

\begin{tabular}{lcc}
\hline & LM & MLFR \\
\hline Intercept $(\alpha)$ & 1.2137 & 0.3424 \\
Standard error of Intercept (s.e $(\alpha))$ & 0.5156 & 0.1820 \\
Probability $\alpha \neq 0$ & 0.0186 & 0.0599 \\
Slope $(\beta)$ & 0.8064 & 0.9341 \\
Standard error of Intercept (s.e( $\beta))$ & 0.0695 & 0.0269 \\
Probability $\beta \neq 1$ & 0.0053 & 0.0142
\end{tabular}

14

15 
16 Table 4 Summary of MLFR model parameters for field $\mathrm{pH}(\mathrm{y})$ and lab $\mathrm{pH}$ data (x) for four scenarios:

17 (Case 1) Experienced and 1PM, (Case 2) Experienced and 5PM, (3) Inexperienced and 1PM and (4) 18 Inexperienced and 5PM.

\begin{tabular}{lcccc}
\hline & Case 1 & Case 2 & Case 3 & Case 4 \\
\hline Intercept $(\alpha)$ & 0.7572 & 0.3477 & 1.5476 & 1.4273 \\
Standard error of Intercept (s.e $(\alpha))$ & 0.3393 & 0.2381 & 0.5273 & 0.4933 \\
Probability $\alpha \neq 0$ & 0.0257 & 0.1443 & 0.0033 & 0.0038 \\
Slope $(\beta)$ & 0.8705 & 0.9178 & 0.8256 & 0.8315 \\
Standard error of Intercept (s.e( $\beta))$ & 0.0430 & 0.0347 & 0.0604 & 0.0580 \\
Probability $\beta \neq 1$ & 0.0026 & 0.0177 & 0.0039 & 0.0037 \\
\hline
\end{tabular}

19

20 
21 Table 5 ANOVA for the absolute difference between lab $\mathrm{pH}$ and field $\mathrm{pH}$ with two kits and twelve 22 levels of $\mathrm{pH}$. Mean values are presented.

\begin{tabular}{lll}
\hline Factor & & Absolute difference \\
\hline Kit Type & Kit 1 & \\
& Kit 2 & 0.603 \\
LSD $(5 \%)$ & 0.473 \\
pH Levels & & 0.0924 \\
& & \\
& 4.5 & 0.372 \\
5.0 & 0.357 \\
5.5 & 0.411 \\
5.5 & 0.481 \\
6.0 & 0.506 \\
6.5 & 0.602 \\
7.0 & 0.653 \\
7.5 & 0.919 \\
8.0 & 0.681 \\
8.5 & 0.602 \\
9.0 & 0.452 \\
9.5 & 0.473 \\
LSD(5\%) & 0.2532 \\
Types of Kits (K) & \\
pH Levels (L) & \\
& & \\
& & \\
& & \\
& & \\
& & \\
& &
\end{tabular}

23

24 